\title{
ARTIGOS
}

\section{DESIGN E BIOMIMÉTICA: UMA REVISÃO SOBRE O ESTADO DA ARTE NO CENÁRIO BRASILEIRO}

\author{
DESIGN AND BIOMIMICRY: A REVIEW OF THE STATE OF THE ART IN THE BRAZILIAN SCENARIO
}

\author{
ALICE ARAUJO MARQUES DE SÁ| UNB \\ DIANNE MAGALHÃES VIANA, Dra.|UNB
}

\begin{abstract}
RESUMO
A Biomimética corresponde à emulação consciente da natureza e oportuniza a inserção de conhecimentos biológicos em atividades criativas. Nessa perspectiva, este artigo tem por objetivo examinar as interfaces entre design e biomimética por meio de uma revisão sistemática da literatura nacional. Para tanto, foram aplicados os descritores "design" AND "biomimética" na base Google Scholar, adotando-se a ferramenta do Enfoque Meta Analítico Consolidado. Desse modo, foi conduzida uma busca por obras no período de 1990 a 2019, totalizando, inicialmente, 211 trabalhos. Levando-se em conta o número de citações, foram selecionadas seis contribuições para ilustrar as pesquisas recentes (entre 2016 e 2019). Observou-se que os temas recorrentes foram: economia circular; ciência dos materiais; formas e processos naturais; prototipagem digital; e percepções do espaço construído. As abordagens proeminentes corresponderam a projetos em design, arquitetura e engenharia, fundamentados em interações do ecossistema. Conclui-se que a natureza representa um vasto repositório de conhecimento e inspiração para designers. Portanto, a biomimética merece ser investigada dado o seu potencial para aprimorar a qualidade de vida e estimular a conservação da biosfera.
\end{abstract}

PALAVRAS CHAVE: Biomimética; Design; Sustentabilidade; Biônica; Bioinspiração

\begin{abstract}
Biomimicry corresponds to the conscious emulation of nature and provides opportunities for the insertion of biological knowledge in human projects. In this perspective, the article aimed to examine the interfaces between design and biomimicry through a systematic review of national literature. For that, the descriptors "design" AND "biomimética" were applied in the Google Scholar database, adopting the tool of Meta Analytical Consolidated Approach. Thus, a search was conducted from 1990 to 2019, initially totaling 211 works. Taking into account the number of citations, six contributions were selected to illustrate recent research (between 2016 and 2019). It was observed that the recurring themes were: circular economy; material sciences; natural forms and processes; digital prototyping; and perceptions of the built space. The prominent approaches corresponded to projects in design, architecture and engineering based on ecosystem interactions. It is concluded that nature represents a vast repository of knowledge and inspiration for designers. Consequently, biomimicry deserves to be investigated given its potential to improve the quality of life and stimulate the conservation of the biosphere.
\end{abstract}

KEYWORDS: Biomimicry, Design, Sustainability, Bionics, Bioinspiration 


\section{INTRODUÇÃO}

O aprimoramento de projetos nas mais diversas áreas do conhecimento humano é inerente aos processos criativos, conforme salientou Cardoso (2012). Especialmente, em design, os profissionais estão em constante busca por configurações, ferramentas e métodos que viabilizem soluções inovadoras. Para tanto, numerosas possibilidades devem ser perscrutadas, algumas das quais podem parecer distantes do cotidiano da maioria dos projetistas, dentre elas, o meio natural (SÁ, 2018).

Dessa forma, o presente artigo visa investigar a literatura nacional de modo a levantar os principais desenvolvimentos e pesquisas conduzidos nas áreas de interface entre a biomimética e o design.

Ora, vale realçar que a natureza dispôs de bilhões de anos para aperfeiçoar seus sistemas de modo que seus integrantes manifestassem formas mais eficientes e adaptadas visando sua sobrevivência (THIÉRY; BRETON, 2017).

Assim, segundo Antonioli (2017), uma pluralidade de organismos - constituintes da esfera biótica do planeta, que envolve seres microscópicos, macroscópicos, vegetais e animais - possuem configurações e estratégias instaladas evolutivamente, as quais podem revelar soluções para desafios persistentes ou emergentes nos variados domínios da existência.

Mas, no decorrer dos últimos séculos, a espécie humana vem alterando radicalmente sua relação com a natureza. De uma interação de pertencimento, fortemente dependente dos ciclos naturais, o ser humano passou a exercer uma posição de superioridade na escala filogenética (DIAS, 2014; PAPANEK, 2007).

Nessa ótica, não apenas se desequilibram as essências dos convívios nos nichos biológicos, como também se restringem ou se aniquilam potencialidades presentes na natureza. Perdem-se referenciais significativos para o bem-estar e o bem-viver em um futuro próximo. Em perspectiva semelhante, convergem os debates impulsionados pelos movimentos de preservação ambiental, as preocupações com as gerações futuras e a adoção de práticas voltadas para eficiência no uso de recursos, redução do consumo e upcycling (CESCHIN; GAZIULUSOY, 2016).

É notório que, nesse cenário, tem evoluído a biomimética, definida como campo do conhecimento que estuda o meio natural e considera organismos como modelos, medidas e mentores de estratégias e recursos para soluções criativas (BENYUS, 1997; ROSSIN, 2010).

Admite-se, portanto, que a natureza constitui um grande repositório de conhecimento e inspiração para profissionais de design e que os aportes da biomimética merecem ser investigados dado o seu potencial para a conservação da biosfera. Ou seja, o embasamento em estudos nessa área pode desvelar uma agenda de pesquisa em design.

Nessa perspectiva, também é importante considerar que os métodos de revisão da literatura viabilizam que pesquisadores ampliem seu arcabouço de informações, observando os desenvolvimentos de proeminência em suas áreas de atuação. Assim, os projetos e as pesquisas são adequadamente embasados em teorias e conceitos, além de haver uma compreensão aprofundada das ferramentas e métodos disponíveis, de modo que sejam selecionados em consonância com cada cenário de exploração e cada projeto. Ademais, em virtude do conhecimento prévio de publicações e pesquisas realizadas na área selecionada para investigação - nesse caso o design e a biomimética - emerge a possibilidade de conduzir diversos estudos, por conseguinte, estimulando a criação de contribuições inovadoras.

Compete ressaltar que, a revisão da literatura quando é aplicada em modo sistemático, reúne um rigor metodológico frequentemente relacionado a índices bibliométricos e análises estatísticas para minimizar os equívocos na seleção de documentos a serem estudados (MARIANO; ROCHA, 2017; PERISSÉ; GOMES; NOGUEIRA, 2001).

Dentre as múltiplas ferramentas de revisão sistemática está a Teoria do Enfoque Meta Analítico Consolidado TEMAC, que segundo Mariano e Rocha (2017), fundamenta-se em leis bibliométricas e abrange três etapas gerais: a) preparação da pesquisa; b) levantamento, apresentação e interconexão de dados; e c) detalhamento, modelo integrador e validação por evidências. Para esses autores, os recursos gerados com tal abordagem suscitam comparações em diversos contextos e oportunizam o desenvolvimento de instrumentos e escalas de mensuração.

Tendo em vista tais pressupostos, estipularam-se as seguintes questões norteadoras para o presente estudo: de que modo a biomimética e o design se interrelacionam nas pesquisas científicas nacionais? Quais são as principais instituições e periódicos que publicam sobre os assuntos? Quais são as abordagens mais recentes dos pesquisadores na área? Os estudos realizados propõem novas formas de utilização dos conceitos?

Em síntese, supõe-se que a natureza constitui uma diretriz relevante em projetos de design e, especialmente, os aportes da biomimética merecem ser mais pesquisados no intuito de produzir conhecimentos teóricos e práticos na área. Conforme já mencionado anteriormente, esse trabalho pretende examinar as relações entre design e biomimética por meio de uma revisão sistemática da literatura e explorar as suas interconexões. 


\section{BIOMIMÉTICA}

O termo Biomimicry - difundido por Janine Benyus (1997) - em sua etimologia reúne radicais que traduzem os conceitos de "vida" e de "mimesis"; isto é, uma aproximação, um devir, um ato de representação. Nessa área do conhecimento, sugere-se que as soluções naturais suscitam potencialidades para obter respostas para adversidades funcionais ou de desempenho viabilizando escolhas mais ajustadas às metas de um projeto. Em outras palavras, busca-se inspiração em formas, especificidades, interrelações e comportamentos de organismos vivos para propor inovações, por exemplo, de ambientes, objetos, obras gráficas e eletrônicas em um cenário de produção (ARRUDA, 2010; ROSSIN, 2010).

Diante do exposto, considera-se que, após bilhões de anos, o processo evolutivo dos organismos no sistema natural instaurou estruturas e funções mais apropriadas para cada contexto, inclusive do ponto de vista da sustentabilidade, pois os recursos ambientais tendem a ser utilizados do modo mais equilibrado possível ao longo do ciclo da vida.

Baseados nessas premissas, estudiosos da biomimética defendem tal perspectiva, mas alertam que este mimetismo não deve se limitar à reprodução intrínseca da forma exibida no meio natural. Ele deve se estender de maneira a examinar tanto seus processos como o ecossistema globalmente (BENYUS, 1997).

É evidente que a biomimética busca traduções e abstrações a partir da observação, pesquisa e compreensão aprofundada do meio natural. $\mathrm{O}$ ato de simplesmente imitar ou copiar organismos, processos e sistemas reduz as possibilidades criativas de inserção desta prática nas atividades tecnológicas. Na realidade, almejam-se analogias, de modo que esses procedimentos se adequem aos princípios biomiméticos (BAUMEISTER; TOCKE; RITTER; DWYER, 2014).

Segundo Benyus (1997) e Arruda (2010), o design biomimético é baseado no funcionamento e organização de processos e fenômenos da natureza, guiando-se pelos seguintes aspectos norteadores:

- Funcionar por meio da luz solar;

- Usar apenas a energia necessária;

- $\quad$ Adequar forma à função;

- Reciclar componentes;

- Recompensar cooperação;

- Enfocar a diversidade;

- Demandar expertise local;

- Lidar com excessos em escalas de complexidade;

- Explorar limites e fronteiras.
Tendo isso em vista, Antonioli (2017), Baumeister, Tocke, Ritter e Dwyer (2014) destacaram três abordagens que caracterizam a integração da biomimética ao processo criativo:

1. Evidência da forma - modo em que as configurações do produto emergem de características físico-biológicas.

2. Aproximação processual - o recurso emulado em design é embasado na análise e transformação de processos e comportamentos orgânicos.

3. Ênfase sistêmica - considera a atividade de projeto a partir do estudo de interrelações entre organismos e seu ecossistema.

Cabe apresentar um breve panorama das pesquisas acerca de biomimética no cenário internacional, para contextualizar o presente estudo. Numerosos projetos são desenvolvidos tendo por fundamentação as contribuições de Benyus (1997) e Baumeister et al. (2014), conforme discutido anteriormente. Suas obras auxiliaram na consolidação do tema e condensaram os princípios dessa área e as suas respectivas etapas de aplicação em projetos, assim como seus procedimentos e ferramentas.

Outras frentes de inserção de conhecimentos naturais no domínio criativo podem ser encontradas na obra de Vincent et al. (2006), que expôs o instrumento TRIZ / BioTRIZ, viabilizador de transferências das noções biológicas para o design, arquitetura e engenharia. Ainda nessa perspectiva, observa-se o uso de analogias bioinspiradas em engenharia, segundo Helms, Vattam e Goel (2009).

Compete assinalar que, uma característica predominante na aplicação de recursos biomiméticos no cenário internacional corresponde ao uso extensivo de ferramentas de modelagem digital, em sua maioria paramétricas (CAD) combinadas com sistemas de prototipagem 3D (AZIZ; EL SHERIF, 2016), como ilustra a Figura 01.

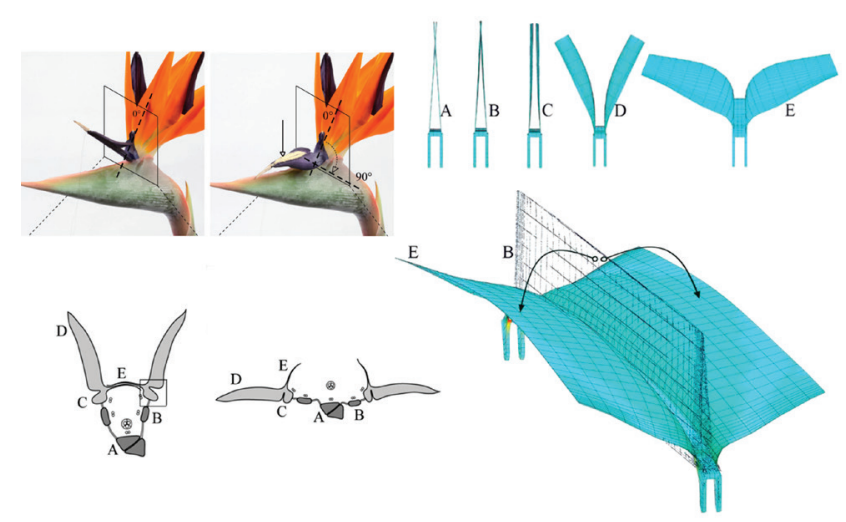

Figura 01 - 0 sistema Flectofin, inspirado na geometria da flor de Strelitzia reginae, viabiliza ajustes de posição em sua estrutura para proteger os espaços da luz do sol Fonte: Lienhard et al. (2012). Disponível em: http://www.simonschleicher.com/flectofin_brochure.pdf 
Além disso, vastos são os estudos de caso apresentados na literatura internacional. A título de exemplo, cita-se o livro de Pawlyn (2011), que abrange construções arquitetônicas biomiméticas (dentre elas, o exemplo ilustrado pela Figura 02), mesclando conceitos naturais com energia limpa, sustentabilidade e sistemas de lixo-zero.
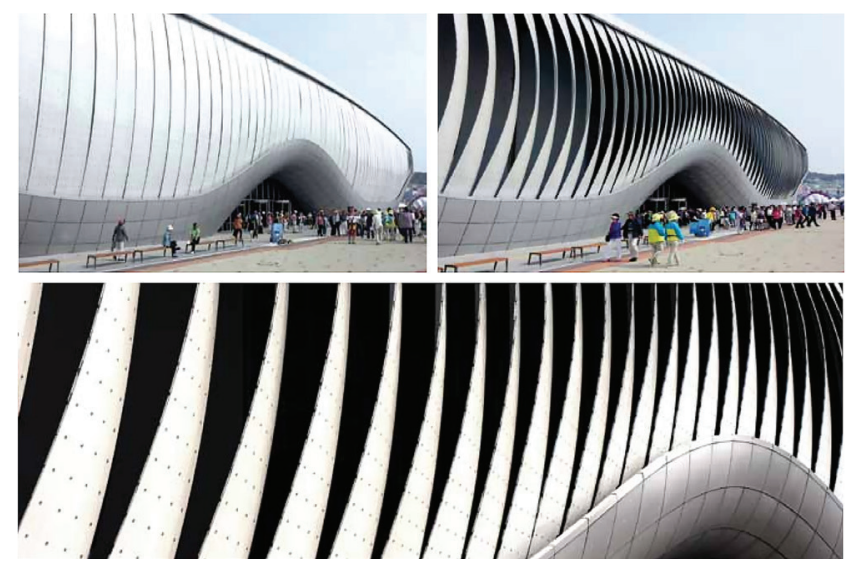

Figura 02 - A fachada do Thematic Pavillion, em Yeosu, na Coréia do Sul, utilizou estruturas Flectofin em sua fachada

Fonte: Lienhard et al. (2012). Disponível em: http://www.simonschleicher.com/flectofin_brochure.pdf

Ainda no âmbito da arquitetura, é relevante recordar as pesquisas de Zari $(2010,2012,2017)$, que propuseram o uso de recursos biomiméticos e metodologias sistêmicas em urbanismo, denominadas "análises de serviços do ecossistema". Nesse sentido, são formulados objetivos quantitativos para regeneração de áreas urbanas. Esse estudo indica que, apesar das dificuldades, os profissionais de design urbano podem atuar de maneira mais sustentável.

Em resumo, nota-se que a biomimética consiste em um recurso de inovação em design, visto que possibilita um enfoque interdisciplinar potencializador da reaproximação do ser humano com a natureza. Nesse sentido, compete a realização de uma busca por trabalhos que permitam caracterizar o cenário nacional sobre o tema.

\section{PROCEDIMENTOS METODOLÓGICOS}

Primeiramente, foi selecionada a base de dados Google Scholar para estabelecer e aplicar os parâmetros condutores da exploração de publicações nacionais. Os levantamentos foram realizados entre os dias 01/01/2020 e 10/01/2020. Iniciou-se a pesquisa a partir do uso dos descritores "biomimética" AND "design". Já o escopo temporal configurado correspondeu ao período entre 1990 e 2019 para a investigação geral da literatura, e, de 2016 a 2019 para a busca por trabalhos mais recentes.

Vale esclarecer que para a obtenção das informações na plataforma Google Scholar, foi utilizado o software
Publish or Perish, que conduz uma busca consolidada de publicações por períodos específicos e palavras-chave.

Nota-se que essa base de dados não disponibiliza filtros automáticos como divisão por áreas do conhecimento, autores de relevância e instituições mais publicadas, tal como ocorre em outros repositórios como a Web of Science ou Scopus. Sendo assim, a extração das informações foi realizada manualmente. Logo, é pertinente informar que os critérios da busca nessa plataforma excluíram somente livros, não sendo as demais obras obrigatoriamente revisadas por pares.

Em seguida, estipulou-se o objetivo de construir interrelações entre as informações coletadas nos trabalhos. Na terceira etapa, com a descrição e o modelo integrador, foram indicadas as possibilidades de pesquisa, as abordagens mais relevantes e as colaborações fundamentais a partir de análises de citation, co-ocurrence e word cloud.

Cabe esclarecer alguns desses vocábulos vinculados à ferramenta TEMAC: citation corresponde à análise da relevância dos autores pela quantidade de citações elencadas na base de dados. Já co-citation verifica artigos, autores, documentos e periódicos frequentemente citados em conjunto e compreende períodos extensos, evidenciando as abordagens mais utilizadas na pesquisa de um determinado tema (MARIANO; ROCHA, 2017).

A análise de coupling estabelece a compreensão de que artigos que citam pesquisas similares revelam associações temáticas e construtivas, isto é, abrange períodos mais curtos para demonstrar as frentes de pesquisa em voga (MARIANO E ROCHA, 2017).

As investigações centradas em palavras-chave correspondem a co-ocurrence, que destaca os termos citados em conjunto em resumos e títulos de artigos, mapeando as principais linhas de pesquisa (MARIANO; ROCHA, 2017).

Já a word cloud, segundo os autores, ilustra um levantamento geral das palavras-chave contidas nos dados extraídos, elencando a frequência de uso de cada termo numericamente e visualmente por meio da cor e do tamanho da tipografia.

Por conseguinte, para obter a visualização dos dados, foi utilizado o software VOSViewer, cujas configurações e parâmetros podem ser ajustados para formular agrupamentos por categorias (clusters) que viabilizam a interpretação dos dados extraídos, gerando mapas de interconexões em redes e nós.

É relevante comentar que a base Google Scholar e sua combinação com Publish or Perish permitem apenas a exportação de metadados cuja distribuição é inadequada para elaborar outras visualizações acerca da literatura no VOSViewer, como mapas de calor para análises de co-citation e coupling. 
Considerando o que foi apresentado anteriormente, foram empregadas outras ferramentas para ilustrar as informações obtidas, como quadros e gráficos do Microsoft Office Word. Já a plataforma TagCrowd possibilitou a obtenção de nuvens de palavras-chave.

A partir de tais levantamentos, foi possível obter o núcleo de autorias, referências e linhas de pesquisa essenciais. Com base nessa extração, iniciou-se a leitura e análise dos trabalhos.

\section{RESULTADOS}

A busca na base Google Scholar visou a obtenção informações acerca da produção nacional. Sendo assim, os termos selecionados foram "biomimética" e "design". O estudo reuniu trabalhos de 1990 a 2019. Os dados foram extraídos com o uso do software Publish or Perish, que gerou um total de 430 publicações.

Constatou-se que o registro mais antigo presente na plataforma datava de 2005. Nota-se, nesse documento, uma aproximação direta ao domínio criativo, uma vez que sua publicação foi realizada após a difusão das perspectivas de Janine Benyus. Desse modo, "A Biomimética e sua Influência no Design e na Arquitetura e Urbanismo" foi um trabalho exposto no XVII Salão de Iniciação Científica (SALÃO DE INICIAÇÃO CIENTÍFICA, 2005). Nele, Panizzutti e Martin apresentaram algumas possibilidades da união de conhecimentos naturais em simbiose com as áreas criativas. Além disso, a manifestação de estudos de caso biomiméticos proporcionou a identificação de novas unidades biológicas que podem estimular o desenvolvimento de propostas estruturais em pequena e larga escala para gerar objetos e espaços adequadamente inseridos no meio ambiente e que não o prejudiquem em sua criação e uso.

Em seguida, foi realizada uma filtragem manual dos trabalhos obtidos, uma vez que o software Publish or Perish e a base Google Scholar não disponibilizavam ferramentas automáticas distribuídas por áreas de conhecimento tal como ocorre nas demais bases de dados internacionais, como, por exemplo, Web of Science e Scopus. Assim, foram retiradas todas as publicações provenientes de temas divergentes como administração, física, medicina, odontologia e química. Dessa forma, restaram obras voltadas para as áreas de design, arquitetura, engenharia, sustentabilidade, preservação ambiental, arte e comunicação. Após tal procedimento, permaneceram 211 publicações.

Considera-se essencial observar que, como a biomimética é uma temática nova, principalmente quando associada ao design, há um número limitado de publicações nacionais em periódicos. Por conseguinte, para o presente levantamento da literatura, foram incluídas todas as contribuições científicas recentes com a exceção de livros; ou seja, foram mantidos periódicos, teses de doutorado, dissertações de mestrado, trabalhos de conclusão de curso, e artigos publicados em anais de eventos.

A etapa seguinte correspondeu ao levantamento de trabalhos de 2016 a 2019, novamente com o uso do software Publish or Perish.

Tendo em vista as singularidades da plataforma, foi inviável gerar mapas de calor de co-citation e coupling. Apesar disso, foram construídos quadros, gráficos, mapas de coocorrência e de palavras-chave no intuito de ilustrar os dados coletados e oportunizar suas análises.

Identificou-se que o autor com maior frequência de publicação foi Amilton José Vieira de Arruda $(n=8)$, seguido por Flora Bittencourt Detanico $(n=5)$ e Theska Laila de Freitas Soares $(n=5)$. Já os estados com maior número de publicações, corresponderam ao Rio Grande do Sul, a São Paulo e a Pernambuco, respectivamente.

Para elencar as principais instituições que pesquisaram e publicaram sobre design e biomimética foi elaborada a Figura 03. Nela, é possível observar que as universidades de maior destaque são: Universidade Federal do Rio Grande do Sul, Universidade Federal de Pernambuco, Universidade de São Paulo e Pontifícia Universidade Católica do Rio de Janeiro.

\section{UFRGS $\square$ UFPE $\square$ USP $\square$ PUC-RIO}

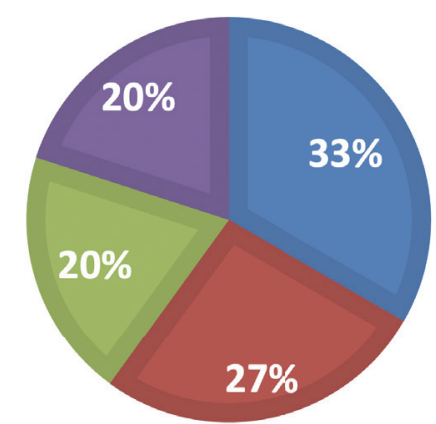

Figura 03 - Instituições que mais publicaram sobre os temas Fonte: As autoras, 2020.

Salienta-se que foi estabelecida uma delimitação para a seleção dos trabalhos. Tal parâmetro correspondeu a todas as obras com 5 ou mais citações, do período de 1990 a 2019, que são apresentadas no Quadro 01. Vale comentar que o Quadro 02 complementa esse conjunto de produções, sendo que exibe todas aquelas que obtiveram apenas 5 citações no mesmo período de investigação. 


\begin{tabular}{|c|c|c|}
\hline Autoria e Título & Citações & Principais Contribuições do Trabalho \\
\hline $\begin{array}{l}\text { Ribeiro; Kruglianskas (2014). } \\
\text { Economia circular no con- } \\
\text { texto europeu: conceito e } \\
\text { potenciais de contribuição } \\
\text { na modernização das polí- } \\
\text { ticas de resíduos sólidos. }\end{array}$ & 23 & $\begin{array}{l}\text { Aborda a relevância do modelo de economia circular, que estabelece ciclos de energias e ma- } \\
\text { teriais na produção para reduzir o consumo e aprimorar a eficiência gerando benefícios para o } \\
\text { ambiente. Esse conceito está relacionado às áreas de gestão do ciclo de vida, ecologia industrial, } \\
\text { design regenerativo e biomimética. Trata os resíduos como fontes de recursos, prevê sistemas } \\
\text { resilientes e possui perspectiva sistêmica que distingue os fluxos de produção. Propõe o reuso, } \\
\text { a substituição de partes e a preferência por substâncias atóxicas. }\end{array}$ \\
\hline $\begin{array}{l}\text { Detanico; Silva; Teixeira (2010). } \\
\text { A biomimética como } \\
\text { método criativo para o } \\
\text { projeto de produto. }\end{array}$ & 14 & $\begin{array}{l}\text { Evidencia o uso de noções da biologia no apuro do arcabouço criativo de designers, em etapas } \\
\text { conceituais e de geração de alternativas. Elenca fatores fundamentais da biomimética e ilustra } \\
\text { aplicações em conjunto com modelos matemáticos e geométricos para gerar produtos resultan- } \\
\text { tes de analogias naturais. }\end{array}$ \\
\hline $\begin{array}{l}\text { Magnago; Aguiar; Paula } \\
\text { (2012). } \\
\text { Sustentabilidade em desen- } \\
\text { volvimento de produtos: } \\
\text { uma proposta para a clas- } \\
\text { sificação de abordagens. }\end{array}$ & 11 & $\begin{array}{l}\text { Classifica quinze abordagens de sustentabilidade no ambiente empresarial e apresenta suas } \\
\text { interconexões. Destaca quando empregá-las e como combiná-las em equipes de Processo de } \\
\text { Desenvolvimento de Produtos. São observados aspectos de responsabilidade ambiental, social } \\
\text { e a geração de valor econômico. A biomimética figura como um campo associado ao Capitalismo } \\
\text { Natural e às Zero Emission Research and Initiatives. }\end{array}$ \\
\hline $\begin{array}{l}\text { Beiguelman (2016). } \\
\text { Da cidade interativa às memó- } \\
\text { rias corrompidas: arte, design e } \\
\text { patrimônio histórico na cultura } \\
\text { urbana contemporânea. }\end{array}$ & 10 & $\begin{array}{l}\text { Destaca ensaios sobre a expansão urbana em redes, memória cultural, arte contemporânea e } \\
\text { suas relações com o meio digital. Pondera sobre os limites entre natureza e cultura em produ- } \\
\text { ções artísticas, como os projetos de Eduardo Kac, que reúnem combinações de DNA seleciona- } \\
\text { das para gerar resultados visuais inovadores em seres vivos. Apresenta o conceito de "próxima } \\
\text { natureza", ou seja, de seres vivos projetados, isto é, "autenticamente artificiais". }\end{array}$ \\
\hline $\begin{array}{l}\text { Filgueiras; Fangueiro; } \\
\text { Raphaelli (2008). } \\
\text { A importância de fibras e fios } \\
\text { no design de têxteis destina- } \\
\text { dos à prática desportiva. }\end{array}$ & 8 & $\begin{array}{l}\text { Representa o progresso na ciência de materiais destinados à confecção de vestimentas e artigos } \\
\text { esportivos. Observa que o uso de tais fibras e superfícies podem aprimorar a eficiência dos atle- } \\
\text { tas. Exibe tecidos inspirados em pele de tubarão para uso em esportes aquáticos, que reduzem } \\
\text { o atrito e oportunizam a hidrodinâmica, consequentemente melhorando o desempenho. }\end{array}$ \\
\hline $\begin{array}{l}\text { Verschleisser (2008). } \\
\text { Aplicação de estruturas de bam- } \\
\text { bu no design de objetos: como } \\
\text { construir objetos leves, resisten- } \\
\text { tes, ecológicos, e de baixo custo. }\end{array}$ & 7 & $\begin{array}{l}\text { Apresenta estudos biomiméticos sobre propriedades do bambu e sua aplicação em estruturas } \\
\text { de tensegrity para a criação de construções leves e resistentes. Também trata da perspectiva de } \\
\text { Buckminster Fuller e de outros especialistas na investigação de atributos naturais em cenários } \\
\text { de projetos arquitetônicos combinando fatores de aproveitamento energético e propriedades } \\
\text { estruturais. }\end{array}$ \\
\hline $\begin{array}{l}\text { Oliveira (2012). } \\
\text { Design de superfície: proposta } \\
\text { de procedimento metodoló- } \\
\text { gico para criação de estam- } \\
\text { pas têxteis com referência } \\
\text { em elementos naturais. }\end{array}$ & 6 & $\begin{array}{l}\text { Revela aplicaçães da biônica, biomimética e do biomorfismo. Averigua três procedimentos de de- } \\
\text { sign de produto baseados em estudos de organismos. Implementa experimentações na criação de } \\
\text { estampas com profissionais e estudantes de design. O estudo conclui que explorar conceitos na- } \\
\text { turais combinados com práticas de desenho manual e prototipagem computadorizada apresenta } \\
\text { potencial para a criação em design gráfico e de produto, bem como para a área da arquitetura. }\end{array}$ \\
\hline
\end{tabular}

Quadro 01: Pesquisas mais citadas e suas principais contribuições na base Google Scholar entre 1990 e 2019.

Fonte: As autoras, 2020.

\begin{tabular}{|c|c|c|}
\hline Autoria e Título & Citações & Principais Contribuições do Trabalho \\
\hline $\begin{array}{l}\text { Queiroz; Araújo; Rattes (2017). } \\
\text { Biônica e biomimética no } \\
\text { contexto da complexidade e } \\
\text { sustentabilidade em projeto. }\end{array}$ & 5 & $\begin{array}{l}\text { Retrata um breve histórico do uso de aportes naturais em projetos humanos. Ilustra os principais } \\
\text { fundamentos da biônica e da biomimética, dentre eles os Princípios da Vida e a perspectiva ho- } \\
\text { lística e transdisciplinar. Os procedimentos que caracterizam o denominado Biomimicry Thinking } \\
\text { consistem em ciclos de projeto contínuos e reiterados em uma escala crescente de complexidade, } \\
\text { baseados nas características essenciais da área: ethos, (re)conexão e emulação. Tais fatores regem } \\
\text { as duas dinâmicas de projeto: "desafio de biologia" e "biologia para o design". O trabalho ainda } \\
\text { abrange estudos de caso como: Speedo, Whale Power, Bionic Car e Sahara Forest Project. }\end{array}$ \\
\hline $\begin{array}{l}\text { Steigleder (2010). } \\
\text { Estudo morfológico da } \\
\text { planta Salvinia molesta: uma } \\
\text { contribuição para a biônica } \\
\text { e o design de produto. }\end{array}$ & 5 & $\begin{array}{l}\text { Examina as particularidades morfológicas da planta aquática Salvinia molesta aplicáveis em pro- } \\
\text { jetos de impermeabilização de superfícies. Implementa análises microscópicas de varredura ele- } \\
\text { trônica e modelos 3D para a caracterização dos elementos desse vegetal: suas estruturas, ceras e } \\
\text { tricomas. Além disso, são propostos usos dos dados coletados em superfícies hidrofóbicas tanto } \\
\text { para proporcionar a construção de fachadas de fácil limpeza e manutenção, como para recobrir } \\
\text { peças metálicas de veículos automotivos. }\end{array}$ \\
\hline $\begin{array}{l}\text { Bergmann; Magalhães (2019). } \\
\text { Strategic design, sustainability } \\
\text { and multiple approaches for } \\
\text { textile experimentation. }\end{array}$ & 5 & $\begin{array}{l}\text { Manifesta a importância da adoção de estratégias em design que contribuam para a sustenta- } \\
\text { bilidade no campo têxtil. Destaca as possibilidades de redução dos impactos ambientais com o } \\
\text { uso de materiais disruptivos tanto no setor de vestuário quanto em design de interiores. Sugere } \\
\text { processos regenerativos no âmbito da reciclagem de materiais na indústria brasileira. Por fim, } \\
\text { apresenta os resultados de experimentações com upcycling a partir de resíduos de revestimen- } \\
\text { to para o solo. O trabalho é direcionado para apreciação e uso de fatores da biotecnologia (bio- } \\
\text { luminescência, microbiologia e novos materiais). }\end{array}$ \\
\hline
\end{tabular}

Quadro 02: Pesquisas com 5 citações e suas principais contribuições na base Google Scholar entre 1990 e 2019.

Fonte: As autoras, 2020 
O repertório obtido permite explicitar as principais abordagens em pesquisa no cenário nacional. Sendo assim, variadas propostas gravitam em torno da sustentabilidade e almejam à preservação ambiental, especialmente no que tange ao desenvolvimento de produtos, à economia circular e aos projetos fundamentados em conceitos biomiméticos e bioinspirados.

Constata-se que os principais organismos investigados são vegetais, artrópodes e seres marinhos. Além disso, outros trabalhos estão voltados para análises microscópicas, sejam elas utilizadas para a geração de superfícies e materiais dotados de propriedades físico-químicas provenientes de elementos bióticos, como para estudos de organismos geneticamente modificados.

Os projetos demonstram aplicações nas áreas de design, arquitetura, engenharia, ciência dos materiais, arte, vestuário esportivo e sustentabilidade.

Visto que a construção do mapa de coupling para o Google Scholar foi inviabilizada, dada a organização dos metadados da plataforma, considerou-se relevante elaborar um novo quadro para exibir as informações das pesquisas recentes, isto é, de 2016 a 2019. De modo a estabelecer um critério de seleção dos trabalhos levantados com o Publish or Perish, foram escolhidos aqueles que continham pelo menos uma ou mais citações para integrar o Quadro 03.

\begin{tabular}{|c|c|c|}
\hline Autoria e Título & Citações & Principais Contribuições do Trabalho \\
\hline $\begin{array}{l}\text { Queiroz; Rattes; Araújo (2017). } \\
\text { Biônica e biomimética no } \\
\text { contexto da complexidade e } \\
\text { sustentabilidade em projeto. }\end{array}$ & 5 & $\begin{array}{l}\text { Retrata um breve histórico do uso de aportes naturais em projetos humanos. Ilustra os princi- } \\
\text { pais fundamentos da biônica e da biomimética, dentre eles os Princípios da Vida e a perspec- } \\
\text { tiva holística e transdisciplinar. Os procedimentos que caracterizam o denominado Biomimicry } \\
\text { Thinking consistem em ciclos de projeto contínuos e reiterados em uma escala crescente de } \\
\text { complexidade, baseados nas características essenciais da área: ethos, (re)conexão e emulação. } \\
\text { Tais fatores regem as duas dinâmicas de projeto: "desafio de biologia" e "biologia para o design". } \\
\text { O trabalho ainda abrange estudos de caso como: Speedo, Whale Power, Bionic Car e Sahara } \\
\text { Forest Project. }\end{array}$ \\
\hline $\begin{array}{l}\text { Soares; Arruda; Balestra; } \\
\text { Hartkopf; Barbosa (2016). } \\
\text { A relação entre a biomimética } \\
\text { e a geodésica de Buckminster } \\
\text { Fuller no planejamento de } \\
\text { construções sustentáveis. }\end{array}$ & 3 & $\begin{array}{l}\text { Interrelaciona a biomimética com as criações geodésicas de Buckminster Fuller, ambas propos- } \\
\text { tas alternativas aos métodos construtivos tradicionais. Destaca os benefícios de sustentabili- } \\
\text { dade e melhoria da qualidade de vida em projetos que abrangem conhecimentos da natureza. } \\
\text { Unem-se a isso, as vantagens construtivas oferecidas pela geometria como: tensegridade, leve- } \\
\text { za, força estrutural, distribuição de temperaturas, ventilação, fluxo de ar e facilidade de monta- } \\
\text { gem. Os conceitos são ilustrados por construções como a Ecocamp Patagônia e os Domos da } \\
\text { Amazon. }\end{array}$ \\
\hline $\begin{array}{l}\text { Arruda; Freitas (2018). } \\
\text { Novas estratégias da bio- } \\
\text { mimética: as analogias no } \\
\text { biodesign e na bioarquitetura. }\end{array}$ & 2 & $\begin{array}{l}\text { Organiza uma breve revisão bibliográfica e demonstra as origens, as definições e os princípios } \\
\text { biomiméticos, exemplificando aplicações no biodesign e na bioarquitetura, como: Ornitóptero, } \\
\text { Velcro, Fastskin, Bionic Car e as obras de Santiago Calatrava. Define analogias biomiméticas, orga- } \\
\text { nizadas em quatro categorias: orgânica, classificatória, anatômica e darwiniana. }\end{array}$ \\
\hline $\begin{array}{l}\text { Soares (2016). } \\
\text { A biomimética e a geodésica } \\
\text { de Buckminster Fuller: uma } \\
\text { estratégia de biodesign. }\end{array}$ & 2 & $\begin{array}{l}\text { Destaca que Buckminster Fuller utilizava a inspiração natural para projetar visando o uso eficiente } \\
\text { de recursos, mesmo antes dos princípios biomiméticos terem sido formalizados. Suas combina- } \\
\text { ções geodésicas viabilizam a construção de abrigos confortáveis, acessíveis e que prezam pela } \\
\text { economia de materiais. Exemplos dessas criações são: Amazon Spheres, Patagonia Ecocamp, Eden } \\
\text { Project, Casa Lotufo e Casa Duvivier. Por fim, alternativas estruturais inspiradas em corais foram } \\
\text { geradas com software Grasshopper. }\end{array}$ \\
\hline $\begin{array}{l}\text { Rocha; Venâncio (2017). } \\
\text { Prototipagem digital pa- } \\
\text { ramétrica orientada ao } \\
\text { design emergencial: o caso do } \\
\text { desastre ambiental MG/ES. }\end{array}$ & 2 & $\begin{array}{l}\text { Propõe soluções infraestruturais inspiradas na fauna do cerrado e, mais especificamente, no } \\
\text { tatu Dasypus novemcinctus para uso em situações emergenciais como no desastre ambiental de } \\
\text { Mariana. Foi elaborado um abrigo multiuso retrátil a partir de softwares de parametrização. } \mathrm{O} \text { ar- } \\
\text { tefato, composto por camadas, pode ser facilmente montado, desmontado e transportado. }\end{array}$ \\
\hline $\begin{array}{l}\text { Silva (2017). } \\
\text { Design paramétrico a partir da } \\
\text { digitalização 3D de geome- } \\
\text { trias da natureza com padrão } \\
\text { de crescimento espiral. }\end{array}$ & 1 & $\begin{array}{l}\text { Salienta as singularidades das geometrias espaciais regidas pelo padrão de crescimento em } \\
\text { espiral observado na natureza. Os aportes dos seguintes fundamentos de projeto foram estu- } \\
\text { dados e aplicados: sequência de Fibonacci, engenharia reversa e design paramétrico. Foram uti- } \\
\text { lizados recursos digitais como Rhinoceros, Grasshopper e scripts Phyton. Estudos de caso com } \\
\text { base em elementos como o abacaxi e a pinha são usados como inspiração para produzir objetos } \\
\text { do cotidiano. }\end{array}$ \\
\hline
\end{tabular}

Quadro 03: Artigos mais citados e suas principais contribuições na base Google Scholar entre 2016 e 2019.

Fonte: As autoras, 2020.

O levantamento de publicações mais recentes na base Google Scholar mostra que as iniciativas predominantes em pesquisa consistem, nomeadamente, em investigações estruturais que combinam propriedades naturais e configurações geodésicas à obra de Buckminster Fuller. Essas composições são muito resistentes e oportunizam o manejo sustentável e a economia de recursos. 
Soma-se a isso as outras vertentes de pesquisa que equivalem ao uso de softwares paramétricos de prototipagem digital para a elaboração de projetos baseados em formas curvas, orgânicas e fluidas. Nota-se que essas conformações podem ser transpostas tanto para originar objetos do cotidiano em pequena escala como para uso em cenários de crise e de desastres ambientais, tal como ilustrado na proposta de abrigo emergencial formulada por Rocha e Venâncio (2017).

Assim, são numerosos os exemplos arquitetônicos e de design propostos. Dentre os organismos que suscitaram maior número de projetos estão: a) seres da esfera biótica marinha, como baleias, peixes, tubarões e radiolárias; b) vegetais como o abacaxi e a pinha; e, c) animais como o tatu.

A etapa seguinte da análise dos dados correspondeu à criação de uma word cloud com as palavras-chave das 211 publicações. A Figura 04 exibe os cinquenta termos cujo dimensionamento e saturação correspondem às principais linhas de pesquisa.

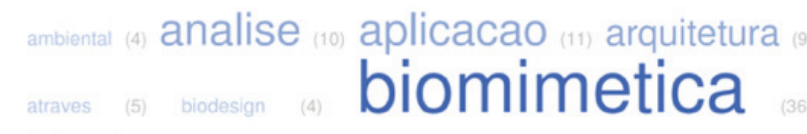

bionica

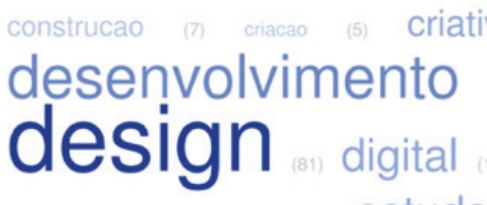

ostampas (4) ostrategia (5) ostrutura (5) estudo (10) ferramenta

metodo

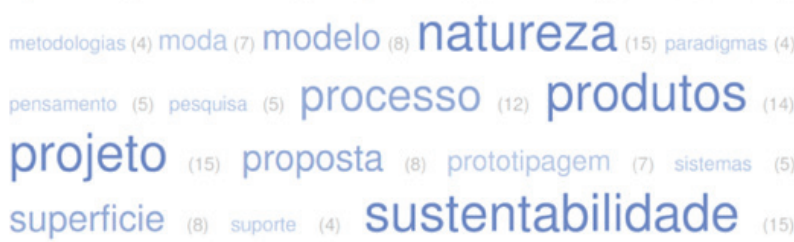

superficie (8) suporte (4) Sustentabilidade

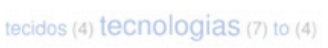

Figura 04 - Word cloud Google Scholar Fonte: As autoras, 2020.

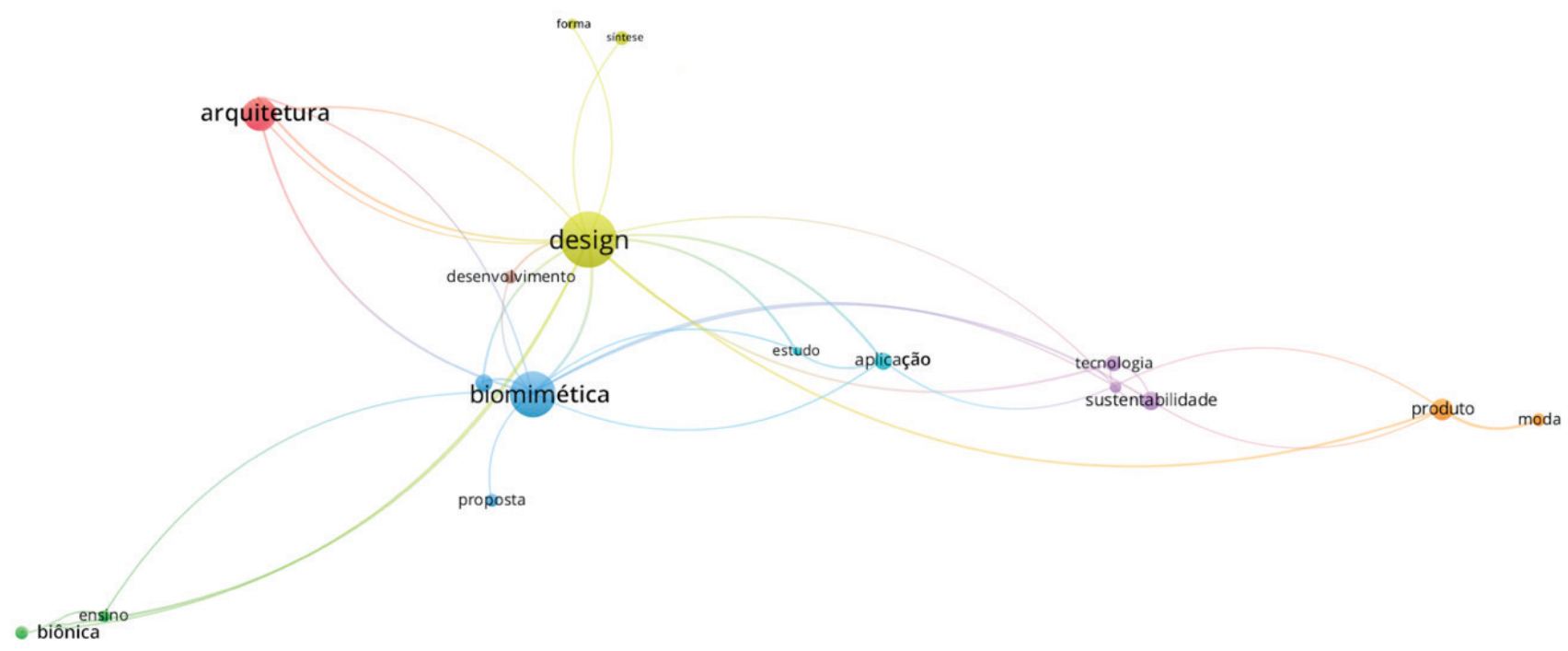

Figura 05 - Mapa de coocorrências.

Fonte: As autoras, 2020.

Verificou-se que o estudo e as aplicações de biomimética em design abrangem perspectivas voltadas para a preservação ambiental e o desenvolvimento de projetos e produtos sustentáveis. Dessa forma, as palavras-chave que mais figuram são, respectivamente: "design". ( $(n=81)$, "biomimética", ( $(n=36)$, "desenvolvimento", $(n=18)$, "sustentabilidade", $(n=15)$, "natureza" $(n=15)$ e "projeto" $(n=$ 15). Infere-se também que é recorrente o uso de tecnologias e ferramentas digitais na formulação de propostas e soluções nessa área.
Outra tendência na pesquisa nacional equivale à atuação nas áreas de arquitetura, construção, moda e ensino em design. É pertinente recordar que a única aplicação disponível no software VOSViewer para a base Google Scholar foi a elaboração do mapa de análise das coocorrências de termos em títulos e resumos. A Figura 05 ilustra as conexões em rede das principais palavras identificadas, sendo que aquelas mais frequentes se sobressaem nos círculos de maiores dimensões interligando os elementos posicionados na região central do diagrama. 
Ao analisar a figura, notou-se que os descritores da pesquisa estão em destaque, seguidos por "arquitetura" e "sustentabilidade". Além disso, verificou-se que a aplicação dos conhecimentos naturais possui relevância tanto em projeto de produtos, no desenvolvimento de tecnologias, bem como no cenário de ensino.

\section{DISCUSSÃO}

A leitura do conjunto de publicações expandiu a compreensão das características enraizadas na biomimética e a transferência de tais conhecimentos para cenários de projeto em design. Constatou-se, por meio da revisão sistemática da literatura, que as interconexões dessas áreas ocorrem com maior intensidade na etapa de projeto conceitual, na geração de alternativas e na formulação de estruturas e materiais. Ademais, muitas dessas pesquisas e aplicações estão associadas aos campos do projeto de produto, da arquitetura, das engenharias e das ciências ambientais.

Além disso, recentemente, os conceitos biológicos estão sendo utilizados em atividades criativas e no design direcionando-se, majoritariamente, a três categorias principais: a) o aprimoramento de configurações formais de objetos com o uso de softwares especializados, de modo a torná-los mais eficientes; b) a aplicação de ferramentas advindas da biomimética como recursos pertencentes ao leque de métodos na área do design, por meio da incorporação de formas e configurações naturais para a criação de objetos, sistemas e espaços; c) a evidência do fator de preservação ambiental, que foi o mais recorrente no levantamento de estudos.

A extração de dados possibilitou formular interpretações sobre o desenvolvimento de pesquisas nacionais. Nesse sentido, o estudo permitiu concluir que no Brasil há um destaque para a produção em design e biomimética nos estados do Sul, Sudeste e Nordeste. Nota-se também que há uma nítida proeminência das instituições públicas dentre os trabalhos.

Contudo, ainda há uma quantidade reduzida de publicações por autores. Soma-se a isso o resultado do presente estudo que demonstrou uma carência de obras com 25 ou mais citações, dado que na base Google Scholar, o trabalho mais citado possuía apenas 23. Acredita-se que isso se deva ao fato de que o maior volume das publicações extraídas dessa base ainda é recente (datam do período entre 2015 e 2019), sendo assim, acredita-se que esse número tenderá a crescer nos próximos anos.

Por conseguinte, após a extensa investigação e análise dos resultados, é possível inferir que a biomimética é uma área ainda em desenvolvimento, que demonstra um grande potencial de crescimento e profusão. Esse domínio pode ser de valioso interesse para elaborar projetos transdisciplinares tanto instigadores de criatividade como encorajadores de práticas de preservação ambiental.

Vale comentar também, que há numerosas aplicações bioinspiradas em arquitetura e design, isto é, que exibem atributos visuais ornamentais, baseados em padrões e formas orgânicas, que todavia não se associam integralmente aos princípios biomiméticos. Desse modo, considera-se importante ressaltar que há uma necessidade do desenvolvimento de mais projetos de design biomimético, principalmente em seu nível mais profundo, abrangendo a ótica do ecossistema. Nela, são considerados os stakeholders envolvidos bem como as particularidades do ciclo de vida. Por consequência, integrar a perspectiva da biomimética gera um maior aproveitamento das propriedades naturais, que podem ser direcionadas a resultados sustentáveis e embasados cientificamente (BAUMEISTER; TOCKE; RITTER; DWYER, 2014).

Considerou-se oportuno adotar contribuições de obras que perscrutam reflexões antropológicas, sociológicas, filosóficas e de design para aprofundar a discussão sobre o tema do presente trabalho.

O ser humano, dotado de um aparato físico limitado, ampliou sua força e sua capacidade de realizar inúmeras tarefas sem modificações anatômicas, em um processo de aprendizagem acumulativa intergeracional, como evidenciou Laraia (1986). Desse modo, participa ativamente de seu próprio processo evolutivo. Todavia, vem se distanciando da natureza ao romper barreiras ambientais e geográficas e adaptando seu "equipamento superorgânico externo", ou seja, sua produção artificial, o que transforma toda a Terra em seu habitat.

Tendo isso em vista, é possível observar uma acentuação do desenvolvimento de tais equipamentos gerados pela humanidade no contexto moderno. Esse cenário, segundo Baudrillard (1973), é marcado por sistemas complexos de objetos efêmeros que estimulam práticas de caráter "consumista" e imediatista, que por sua vez fazem com que as pessoas sejam estimuladas a não tomarem decisões definitivas e duradouras.

Compete assinalar que, de acordo com Dohmann (2013), o ser humano passou a vivenciar situações em que os objetos orbitam ao seu redor em processos fluidos e instáveis e configuram o núcleo das interações e comportamentos, inserindo-se em uma dinâmica incessante de produção global. Tal "objeto-centrismo", em que o ser humano, ao invés de se libertar dos grilhões materiais e adquirir mais autonomia e liberdade a partir 
de suas criações, transforma-se, na verdade, em uma "odisseia do artificial". Consequentemente, a espécie humana vive cada vez mais em locais construídos, circundada por elementos artificiais e imersa em universos projetados, que, tomados em seu conjunto, ditam as relações grupais e direcionam a percepção identitária, os modos de expressão e o aprendizado.

Já Edgar Morin (2007), refletiu sobre a degradação de sistemas naturais em consequência do impacto da produção industrial. Para ele, o mundo globalizado encontra-se cada vez mais imerso em cenários de crise, desencadeadas pelo desenvolvimento sem regulamentações, que, por sua vez, geram retroações graves. Morin (2007) enfatizou que os modelos atuais regentes das práticas humanas estão atingindo seus limites e a noção superficial de "desenvolvimento sustentável" pode ser criticada, uma vez que essa expressão pode conduzir a posicionamentos passivos e soluções estáticas. Conforme retratado pelo autor, é imperativo encontrar um novo caminho, a partir do reconhecimento da inevitabilidade da catástrofe. Nessa ótica, os sistemas inadequados devem se metamorfosear durante sua desintegração a partir da união com fatores complexos e soluções ativas, potencializando caminhos inovadores de regeneração.

Vale acrescentar a isso a visão de Papanek (2007). Para ele, é essencial retomar um posicionamento humilde e reconhecer a responsabilidade ecológica da humanidade, integrando princípios éticos nos projetos e construções de forma que seja possível encontrar um modo de vida adequado e harmônico para com o ambiente. Em outras palavras, para o autor, o design deve ser positivo e unificador, construindo uma ponte entre as necessidades humanas, a cultura e a ecologia.

Logo, é crucial que os designers considerem aspectos como o ciclo de vida de produtos e processos. Isso posto, é relevante considerar os aspectos associados à escolha dos materiais, processos de fabrico, as configurações de embalagens e acabamentos de produtos, o seu transporte, consumo e descarte (PAPANEK, 2007). Vale lembrar que Cardoso (2012) discutiu a transitoriedade de valores e significados associados aos artefatos. Segundo ele, se um objeto realiza uma multiplicidade de funções acaba por obter uma sobrevida maior e "resiste" a seu projeto.

Então, por meio da ressignificação, reciclagem, reutilização e mudança de contexto, prolonga-se a vida útil de artefatos e evita-se seu descarte. Somando-se a isso, é crucial que os designers avaliem as consequências de suas criações antes de implementá-las e busquem compreender a natureza e preservá-la (CARDOSO, 2012; PAPANEK, 1985).
Procedimentos alicerçados na inspiração natural como a biomimética e o cradle to cradle convergem com as ideias de Cardoso (2012) no que concerne o design reversível, modular e durável. É interessante mencionar, ainda, que Braungart e McDonough (2013) argumentaram que é vital manter ciclos renováveis de matérias biológicas e tecnológicas para o bem-viver da humanidade no futuro.

Considera-se ainda que observar e analisar aspectos, tanto da ciência régia como das ciências tradicionais (provenientes das comunidades locais e dos povos indígenas), oportuniza a criação de propostas inéditas, uma vez que a união de ambas demonstra potenciais valiosos para a conservação da biosfera e permite mitigar as consequências de mudanças climáticas sobre os grupos humanos. Nesse sentido, conforme destacou Cunha (2014), o Brasil encontra-se em uma situação especial. Seu privilégio consiste na ampla disposição de recursos biológicos e de conhecimento tradicional, sendo, simultaneamente, um país dotado de equipamento científico que lhe confere a capacidade de valorizar tal patrimônio. Mas, é imprescindível fazer um uso consciente e respeitoso desse rico arcabouço para que os valores tradicionais e a biodiversidade sejam reconhecidos e preservados.

A obra de Cunha (2014) é muito relevante, principalmente, no atual cenário, marcado pelo agravamento das consequências da crise climática, pelas inúmeras queimadas, enchentes e desmatamentos - sobretudo em território amazônico - que destroem a rica biodiversidade nacional, somados às discussões inquietantes sobre os direitos das populações tradicionais e indígenas, que possuem um papel relevante na conservação ambiental, direta e indiretamente.

Essas perspectivas deveriam ser igualmente consideradas nas discussões acerca da preservação ambiental. Em vista disso, é essencial conservar os biomas brasileiros e dar voz às comunidades locais e, principalmente, proteger seu conhecimento e aplicá-lo de modo respeitoso, para que seja possível manter esse amplo repositório do saber passível de aplicação em projetos de design biomimético no futuro.

Diante do exposto, a biomimética pode ser uma estratégia para oportunizar novas abordagens, que instiguem os indivíduos e os tornem mais ativos e pensantes. Principalmente em âmbito sistêmico, conforme evidenciaram Baumeister et al. (2014), Benyus (1997) e Zari (2012), é importante estimular o contato com ambientes naturais e a conscientização da necessidade de preservação da biosfera.

Por fim, destaca-se que, de acordo com Cardoso (2012) e Papanek (2007), dentre as principais competências desejáveis para os designers, estão a preocupação com o 
âmbito das investigações ecológicas e sociais. Além disso, os autores complementaram que é essencial que esses estudantes e profissionais tenham uma formação plural, associando os estímulos inventivos, o pensamento abstrato, a busca por conhecimentos e a atuação em pesquisa com as investigações ecológicas e sociais. Assim, o profissional de design deve estar apto a investigar, organizar e inovar de modo a construir propostas adequadas aos problemas de projeto. Dessa forma, através de testes, modelos e protótipos executados com rigor técnico, é imprescindível considerar também os fatores sociais e as consequências ambientais, ecológicas, econômicas e políticas provocadas por suas criações, uma vez que impactam uma pluralidade de indivíduos (e espécies) ao redor do globo. Nesse escopo, é evidente que a biomimética pode ser de grande interesse para essa construção do conhecimento e da produção em design. Em vista disso, Cardoso (2012) também afirmou que será possível estimular a capacitação de designers para atuar em cenários complexos, cultivando sua criatividade para o bem-viver da sociedade e a sobrevivência do planeta.

\section{CONSIDERAÇÕES FINAIS}

O presente trabalho reforça que o pensamento interdisciplinar é essencial como recurso de inovação tanto para a atividade em design como em áreas correlatas (arquitetura e engenharia) pois, conforme evidenciou Laraia (1986), é precisamente a manipulação criativa do patrimônio cultural (e natural) que instiga a geração de novas propostas. Vale retomar que a genialidade da natureza contou com bilhões de anos para testar e aprimorar suas criações. Isso posto, é preciso considerar que organismos vivos podem suscitar soluções para os desafios da esfera humana.

A revisão implementada corroborou que as interfaces entre a biomimética e o design consistem, sobretudo, na combinação de saberes interdisciplinares; principalmente, no que concerne o contato com o campo da biologia. Então, estruturas, mecanismos, comportamentos e interrelações são considerados nos variados níveis ecológicos e podem ser associados aos princípios de projeto e produção em design. Tendo esses elementos em vista, é possível desenvolver produtos e sistemas mais resilientes, eficientes e mais adaptados às funções requeridas, contribuindo também, para a preservação ambiental, em última instância.

Em outras palavras, a biomimética oportuniza, simultaneamente, tanto a união de características naturais para melhorar a qualidade de vida do ser humano, como a incorporação de práticas e conhecimentos que podem estimular a sustentabilidade e a preservação da biodiversidade.
Nota-se que a Teoria do Enfoque Meta Analítico Consolidado é uma ferramenta que possibilita o mapeamento da literatura, das principais abordagens metodológicas e de tendências para a formulação de uma agenda de pesquisa.

É oportuno observar que, como não foi possível implementar a análise coupling de modo integral para a base Google Scholar, os trabalhos nacionais de 2016 a 2019 foram selecionados manualmente. No entanto, tal critério de escolha pode ter deixado algumas obras de relevância sem a análise adequada, uma vez que ainda não possuem citações devido à sua publicação mais recente. Neste caso, indica-se a realização de uma nova revisão, de caráter qualitativo, em que sejam escolhidos mais trabaIhos inseridos no contexto do design biomimético.

Ainda, considera-se pertinente efetuar investigações em outras bases de dados. Além disso, recomenda-se a pesquisa com outros termos descritores como: "biônica", "biomimetismo" e "bioinspiração" associados ao termo "design".

\section{REFERÊNCIAS}

ANTONIOLI, Manola. Biomimétisme: science, design et architecture. Dijon, França: Éditions Loco, 2017. 144 p.

ARRUDA, Amilton. Como a biônica e biomimética se relacionam com as estruturas naturais na busca de um novo modelo de pesquisa projetual. Brasil: UFPE, 2010. p. 1-9. Disponível em: <https://fido.palermo.edu>. Acesso em: 27 nov. 2019.

ARRUDA, Amilton; FREITAS, Theska Laila de. Novas estratégias da biomimética: as analogias no biodesign e na bioarquitetura. Mix Sustentável, Florianópolis, v. 4, n. 1, p. 73-82, 1 mar. 2018. Disponível em: <www.sites.ojs.ufsc.br>. Acesso em: 1 jan. 2020.

AZIZ, Moheb Sabry; EL SHERIF, Amr Y. Biomimicry as an approach for bio-inspired structure with the aid of computation. Alexandria Engineering Journal, Alexandria, Egito, v. 55, n. 1, 707-714 2016. Disponível em: < www.sciencedirect.com>. Acesso em: 1 jan. 2020.

BAUDRILLARD, Jean. O sistema dos objetos. São Paulo, Editora Perspectiva, 1973. 232 p.

BAUMEISTER, Dayna; TOCKE, Rose; RITTER, Sherry; DWYER, Jamie. Biomimicry resource handbook: a seed bank of best practices. Montana, Estados Unidos: Biomimicry 3.8, 2014. 285 p.

BEIGUELMAN, Giselle. Da cidade interativa às memórias corrompidas: arte, design e patrimônio histórico na cultura urbana contemporânea. 2016. 
303 f. Tese de Livre-Docência (Livre-Docência em Arquitetura e Urbanismo), Universidade de São Paulo, 2016. Disponível em: <https://teses.usp.br>. Acesso em: 5 jan. 2020.

BENYUS, Janine. Biomimicry: innovation inspired by nature. New York, Estados Unidos: William Morrow and Company, 1997. 324 p.

BERGMANN, Márcia; MAGALHÃES, Cláudio Freitas de. Strategic design, sustainability and multiple approaches for textile experimentation. Global Fashion 2018, Rio de Janeiro, p. 1-23, 2019. Disponível em: <http://gfc-conference.eu>. Acesso em: 1 jan. 2020. BRAUNGART, Michael; MCDONOUGH, William. Cradle to cradle: criar e reciclar ilimitadamente. Espanha: GG Barcelona, 2013. 192 p.

CARDOSO, Rafael. Design para um mundo complexo. São Paulo: Cosac Naify, 2012. 264 p.

CESCHIN, Fabrizio; GAZIULUSOY, Idil. Evolution of design for sustainability: from product design to design for system innovations and transitions. Design Studies, v. 47, p. 118-163, 2016. Disponível em: <https://reader.elsevier.com>. Acesso em: 30 nov. 2019.

CUNHA, Manuela Carneiro da. Cultura com Aspas. São Paulo: Cosac Naify, 2014. 440 p.

DETANICO, F. B.; TEIXEIRA, F. G.; SILVA, T. L. Koltermann da. A biomimética como método criativo para o projeto de produto. Design \& Tecnologia, Rio Grande do Sul, v. 1, n. 2, p. 101-113, dez. 2010. Disponível em: </ www.ufrgs.br>. Acesso em: 1 jan. 2020.

DIAS, Eduardo. A natureza no processo de design e no desenvolvimento do projeto. São Paulo: Senai, 2014. 160 p.

DOHMANN, Marcus et al. A experiência material: a cultura do objeto. Rio de Janeiro: Rio Books, 2013. 272 p.

FILGUEIRAS, Araguacy; FANGUEIRO, Raul; RAPHAELLI, Nathália. A importância de fibras e fios no design de têxteis destinados à prática desportiva. Estudos em Design, Rio de Janeiro, v. 15, n. 1, p. 1-20, 2008. Disponível em: <www.maxwell.vrac.puc-rio.br>. Acesso em: 1 jan. 2020.

HELMS, Michael; VATTAM, Swaroop S.; GOEL, Ashok, K. Biologically inspired design. Design Studies, v. 30, n. 5, p. 127-152, 2009.

LARAIA, Roque de Barros. Cultura: um conceito antropológico. Rio de Janeiro: Jorge Zahar, 1986. 120 p.

LIENHARD, Julian; SCHLEICHER, Simon; POPPINGA, Simon; MASSELTER, Tom; MÜLLER, Lena; SARTORI, Julian. Flectofin: A hingeless flapping mechanism inspired by nature International Bionic-Awards 2012 Techtextil Innovation Prize 2011. Stuttgart, Alemanha: Institute of Building Structures and Structural Design, 2012. 18 p. Disponível em: http://www.simonschleicher.com/flectofin_brochure.pdf. Acesso em: 19 ago. 2020.

MAGNAGO, Patrícia Flores; AGUIAR, João Pedro Ornaghi de; PAULA, Istefani Carisio de. Sustentabilidade em desenvolvimento de produtos: uma proposta para a classificação de abordagens. Produção Online Revista Científica Eletrônica de Engenharia de Produção, Florianópolis, SC, v. 112, n. 2, p. 351-376, 15 abr. 2012. Disponível em: <https://producaoonline.org.br> Acesso em: 1 jan. 2020.

MARIANO, A.M; ROCHA, M.S. Revisão da literatura: apresentação de uma abordagem integradora. AEDM International Conference - Economy, Business and Uncertainty: Ideas for a European and Mediterranean industrial policy. Reggio Calabria (Italia), p. 427- 443, 2017.

MORIN, Edgar. Vers l'abîme? Paris: Éditions de L'Herne, 2007. $181 \mathrm{p}$.

OLIVEIRA, Monique Aline Arabites de. Design de superfície: proposta de procedimento metodológico para criação de estampas têxteis com referência em elementos naturais. Orientador: Evelise Anicet Rüthschilling. 2012. 159 f. Dissertação de Mestrado UFRGS , Porto Alegre, 2012. Disponível em: <https:// lume.ufrgs.br>. Acesso em: 1 jan. 2020.

PAPANEK, Victor. Arquitectura e design: ecologia e ética. Lisboa, Portugal: Edições 70, 2007. 286 p.

PAPANEK, Victor. Design for the real world. Human Ecology and Social Change. Londres: Thames \& Hudson, 1985. 480 p.

PAWLYN, Michael. Biomimicry in architecture. Londres: RIBA Publishing, 2011. 171 p.

PERISSÉ, A. R., GOMES, M. D. M., NOGUEIRA, S. A. Revisões sistemáticas (inclusive metanálises) e diretrizes clínicas. Gomes $M$ da $M$ (org). Medicina baseada em evidências: princípios e práticas. Rio de Janeiro: Reichmann \& Affonso, 2001.

QUEIROZ, Natália; RATTES, Rafael; ARAÚJO, Rodrigo Barbosa de. Biônica e biomimética no contexto da complexidade e sustentabilidade em projeto, p. $127-$ 144. Design \& Complexidade. São Paulo: Blucher, 2017.

RIBEIRO, Flavio de Miranda; KRUGLIANSKAS, Isak. A economia circular no contexto europeu: Conceito e potenciais de contribuição na modernização das políticas 
de resíduos sólidos. XVI Encontro Internacional sobre Gestão Empresarial e Meio Ambiente ENGEMA, São Paulo, p. 1-16, 2014. Disponível em:<www.engema.org.br/16/>. Acesso em: 5 jan. 2020.

ROCHA, Bruno $M$; VENÂNCIO, Leonardo V. Prototipagem digital paramétrica orientada ao design emergencial: o caso do desastre ambiental mg/ es. EuroElecs 2017, São Leopoldo, p. 1751-1760, maio 2017. Disponível em: <https://docplayer.com.br/>. Acesso em: 1 jan. 2020.

ROSSIN, Karen Jonhson. Biomimicry: nature's design process versus the designer's process. WIT Transactions on Ecology and the Environment, Miami, Estados Unidos, v. 138, p. 559-570, 2010. Disponível em: <www.witpress.com>. Acesso em: 30 nov. 2019.

SÁ, Alice Araujo Marques de. Design, inovação e estratégias naturais: aplicações de princípios biomiméticos e biofílicos em projetos criativos. Orientador: Nayara Moreno de Siqueira, Fátima Santos Aparecida. 2018. 112 p. Trabalho de Conclusão de Curso (Graduação em Design) - Universidade de Brasília, Brasília, 2018.

SALÃO DE INICIAÇÃO CIENTíFICA, 17., 2005, Porto Alegre. A biomimética e sua influência no design e na arquitetura e urbanismo. Porto Alegre: 2005. Disponível em: https://lume.ufrgs.br/>. Acesso em: 1 fev. 2020.

SILVA, Luciano Santos da. Design paramétrico a partir da digitalização 3D de geometrias da natureza com padrão de crescimento espiral. Orientador: Fábio Pinto da Silva. 2017. 114 f. Dissertação de Mestrado (Mestrado em Design) - UFRGS, Porto Alegre, 2017. Disponível em: <https://lume.ufrgs.br>. Acesso em: 1 jan. 2020.

SOARES, Theska Laila de Freitas. A biomimética e a geodésica de Buckminster Fuller: uma estratégia de biodesign. Orientador: Amilton José Vieira de Arruda. 2016. 287 f. Dissertação de Mestrado (Mestrado em Design) - Universidade Federal de Pernambuco, Pernambuco, 2016. Disponível em: <repositorio.ufpe. br>. Acesso em: 1 jan. 2020.

SOARES, Theska Laila de Freitas; ARRUDA, Amilton José Vieira de; HARTKOPF, C. L. F.; BARBOSA, J. S. N.; BALESTRA, R. F. P. A relação entre a biomimética e a geodésica de Buckminster Fuller no planejamento de construções sustentáveis. Pluris $20167^{\circ}$ Congresso Luso-Brasileiro para o Planejamento Urbano, Regional, Integrado e Sustentável: Contrastes,
Contradições e Complexidades, Maceió, p. 1-11, 5 out. 2016. Disponível em: <www.fau.ufal.br>. Acesso em: 1 jan. 2020.

STEIGLEDER, Ana Paula. Estudo morfológico da planta Salvinia molesta: uma contribuição para a biônica e o design de produto. 2010. 102 p. Dissertação de Mestrado (Mestrado em Design) - UFRGS, Rio Grande do Sul, 2010. Disponível em: <https://lume.ufrgs.br>. Acesso em: 1 jan. 2020.

THIÉRY, Alain; BRETON, Charles. Biomimétisme: on n'a rien inventé! Paris, França: Le Cavalier Bleu Éditions, 2017. 136 p.

VERSCHLEISSER, Roberto. Aplicação de estruturas de bambu no design de objetos: como construir objetos leves, resistentes, ecológicos, e de baixo custo. Orientador: José Luiz Mendes Ripper. 2008. Tese de Doutorado (Doutorado em Design) - PUC-Rio, Rio de Janeiro, 2008. Disponível em: <http://www2.dbd.puc-rio.br> Acesso em: 1 jan. 2020. 229 p.

VINCENT, J. F. V.; BOGATYREVA, O. A.; BOGATYREV, N. R.; BOWYER, A.; PAHL, Anja Karina. Biomimetics: its practice and theory. Reino Unido: Journal of the Royal Society Interface, v. 3, p. 471-482, 2006.

ZARI, Maibritt Pedersen. Biomimetic design for climate change adaptation and mitigation. Architectural Science Review, v. 53, n. 2, p. 171-183, 2010. Disponível em: <https://researchgate.net>. Acesso em: 1 jan. 2020. ZARI, Maibritt Pedersen. Biomimetic urban design: ecosystem service provision of water and energy. Buildings, v. 7, n. 1., p. 1-13, 2017. Disponível em: <https://researchgate.net>. Acesso em: 1 jan. 2020.

ZARI, Maibritt Pedersen. Ecosystem services analysis for the design of regenerative urban built environments, Wellington, Nova Zelândia, Victoria University of Wellington, 2012. 490 p. Disponível em: <https://researchgate.net>. Acesso em: 1 jan. 2020. 


\section{AUTORES}

ORCID: https://orcid.org/0000-0003-4815-1353

ALICE ARAUJO MARQUES DE SÁ | Universidade de Brasília | Programa de Pós-Graduação em Design | Brasília, Distrito Federal (DF) - Brasil Correspondência para: SQN 205 Bloco E ap. 506 - Asa Norte, Brasília - DF | CEP 70843-050 E-mail: alicearaujoms@gmail.com

ORCID: https://orcid.org/0000-0001-8396-8022

DIANNE MAGALHÃES VIANA, DRA. | Universidade de Brasília | Programa de Pós-Graduação em Design | Brasília, Distrito Federal (DF)- Brasil | Correspondência para: Campus Universitário Darcy Ribeiro Instituto Central de Ciências - Ala Norte, Subsolo - Módulo 18 Asa Norte, Brasília-DF | CEP 70910-900 | E-mail: dianne.magav@gmail.com

\section{COMO CITAR ESTE ARTIGO}

SÁ, Alice Araujo Marques de; VIANA, Dianne Magalhães. Design E Biomimética: Uma Revisão Sobre O Estado Da Arte No Cenário Brasileiro. MIX Sustentável, [S.I.], v. 7, n. 1, p. 137-150, dez. 2020. ISSN 24473073. Disponível em:<http://www.nexos.ufsc.br/index.php/ mixsustentavel>. Acesso em: dia mês. ano. doi:https:// doi.org/10.29183/2447-3073.MIX2020.v7.n1.137-150. 